\title{
Cannibalism in a grapsid crab, Hemigrapsus penicillatus
}

\author{
Yasushi Kurihara, Kazutoshi Okamoto \\ Biological Institute, Faculty of Science, Tohoku University, Sendai 980, Japan
}

\begin{abstract}
Cannibalism and population dynamics of the grapsid crab Hemigrapsus penicillatus were investigated in a brackish lagoon in northeastern Japan, and in the laboratory. Crabs with carapace width $<0.5 \mathrm{~cm}$ were frequently preyed upon by larger individuals; prey size appeared to be related to the maximum gape of predator chelae. Field studies revealed that a rapid decrease in the number of small crabs occurred following a great increase as a result of settling of juvenile crabs in the fall. This was concluded to be caused by cannibalism. The availability of shelter such as narrow gaps between boulders and stones limited cannibalism. Avoidance of large individuals by small ones, and visual approach of large individuals to small ones, as well as the presence of suitable shelter for small crabs, are considered important factors in maintaining the stability of the $H$. penicillatus population.
\end{abstract}

\section{INTRODUCTION}

Hemigrapsus penicillatus (De Haan) inhabits littoral and sublittoral boulder environments in the brackish lagoons and estuaries of Japan. Okamoto \& Kurihara (1987) investigated the life cycle and population dynamics of $H$. penicillatus, and reported that 2 ageclass populations coexist in the same season and that the species life span is $2 \mathrm{yr}$ The coexistence of 2 ageclasses suggests the possibility of cannibalism, that is, intraspecific predation, since it is well known that cannibalism is common in a wide variety of animals (Fox 1975, Polis 1981). Although cannibalism may be useful for regulating population density, a brake is necessary since excessive cannibalism would be disadvantageous to the survival of a species.

In the present study, seasonal changes in the numbers of small and large crabs, and effects of the presence of larger crabs on the density of small crabs, were investigated in the field. In addition laboratory experiments were performed to investigate the conditions leading to cannibalism and the mechanism of cannibalism-avoidance from ecological and behavioural viewpoints.

\section{MATERIALS AND METHODS}

Field observations. To examine seasonal changes in the growth and population density of Hemigrapsus penicillatus in brackish-water stone piles, 3 plastic baskets $(45 \times 28 \times 18 \mathrm{~cm}$ height), each filled with 25 stones ( 7 to $10 \mathrm{~cm}$ in diameter) were placed in a brackishwater lagoon in northeastern Japan $\left(38^{\circ} 15^{\prime} \mathrm{N}, 141^{\circ} 01^{\prime}\right.$ E) for $10 \mathrm{mo}$ from June 1986 until April 1987. These baskets were carefully pulled up from the water every 1 or 2 mo and the number of $H$. penicillatus found in the spaces between the stones in each basket was counted and their carapace widths (CW) measured.

Four plastic boxes $(42 \times 32 \times 14 \mathrm{~cm}$ height $)$ filled with 25 stones ( 7 to $10 \mathrm{~cm}$ in diameter) were placed on the bottom of the brackish lagoon to determine the effects of the presence of large Hemigrapsus penicillatus on the density of small ones. Three of the stone-filled boxes were covered with wire netting $(1.3 \times 1.3 \mathrm{~cm}$ mesh $)$ to prevent entry of individuals with $\mathrm{CW}>1.3 \mathrm{~cm}$ and to allow only smaller individuals in. The remaining box was left open. Into the 3 netted boxes were placed, respectively, 10 large males (CW ca $2.2 \mathrm{~cm}), 10$ large individuals with chelae removed, or no large individuals. Ten $\mathrm{d}$ after setting, the 4 boxes were recovered and the number of individuals in each box and carapace widths were measured. This examination was performed 4 times from late October to late November, a period during which the population density of settled juvenile crabs is known to increase dramatically (Okamoto \& Kurihara 1987).

Laboratory observations. To examine relationships between sizes of prey and predator, boxes $(34 \times 28 \times$ 
$12 \mathrm{~cm}$ height) filled with seawater (20\% salinity) to a depth of $7 \mathrm{~cm}$ were placed in a constant-temperature room at $25^{\circ} \mathrm{C}$. To each box, 10 prey (2 each of $\mathrm{CW} 0.5$. $1.0,1.5,2.0$ and $2.5 \mathrm{~cm}$ ), with their chelae removed to prevent feeding on each other, and one predator starved for $7 \mathrm{~d}$ were added. The predators were male and female crabs with CW 0.5, 1.0, 1.5, 2.0 and $2.5 \mathrm{~cm}$. In this manner, 10 prey of different sizes and one predator were kept in the same box for $24 \mathrm{~h}$ and the number of remaining prey was then counted. Each experiment was repeated 4 times. Relationships between carapace width and maximum gape of the chelae in males and females were also determined. Maximum gape was expressed as the greatest distance between the tips of the movable and fixed chelae.

To examine the effects of shelter, 2 boxes $(42 \times 32 \times$ $14 \mathrm{~cm}$ height) filled with $20 \%$ salinity seawater to a depth of $7 \mathrm{~cm}$ were prepared, both containing 5 narrow PVC pipes (inner diameter $1 \mathrm{~cm}$, length $10 \mathrm{~cm}$ ) and 5 wide pipes (inner diameter $2 \mathrm{~cm}$, length $10 \mathrm{~cm}$ ). Only one small crab was able to enter a narrow pipe and one large individual a wide pipe. One of the boxes contained 5 large males $(\mathrm{CW} \mathrm{ca} 2 \mathrm{~cm}$ ) and 5 small individuals ( $\mathrm{CW}$ ca $0.5 \mathrm{~cm}$ ) and the other box 5 large and 20 small individuals. The surviving number of small individuals in each box was then observed daily and the experiment was repeated 3 times.

Two boxes $(42 \times 32 \times 14 \mathrm{~cm}$ height) were filled with $20 \%$ salinity seawater to a depth of $7 \mathrm{~cm}$. Sessile matter striped from the surface of stones in the field, mainly microalgae, bacteria and detritus, which is possibly a food source for Hemigrapsus penicillatus in the lagoon, was spread over the bottom of one box. The other box acted as a control (no sessile matter). One large male $(\mathrm{CW} \mathrm{ca} 2 \mathrm{~cm}$ ) and 10 small individuals (CW ca $0.5 \mathrm{~cm}$ ) were transferred to each box and surviving crabs after 5, 10 and $15 \mathrm{~d}$ were counted. The experiment was repeated 3 times.

To analyze factors inducing contact between large and small individuals under conditions of co-existence, one large male ( $\mathrm{CW}$ ca $2 \mathrm{~cm}$ ) and 3 small individuals $(\mathrm{CW}$ ca $0.5 \mathrm{~cm})$ were placed into a box $(28 \times 22 \times 16$ $\mathrm{cm}$ height) filled with $20 \%$ salinity seawater and the frequency of their contact was measured. In this experiment, small and large individuals, either intact or with their eyes removed, were used. Observation was made for 10 min each time, 5 times.

\section{RESULTS}

\section{Field observations}

Fig. 1 shows seasonal changes in the number of crabs with different carapace widths, that is, small individu-

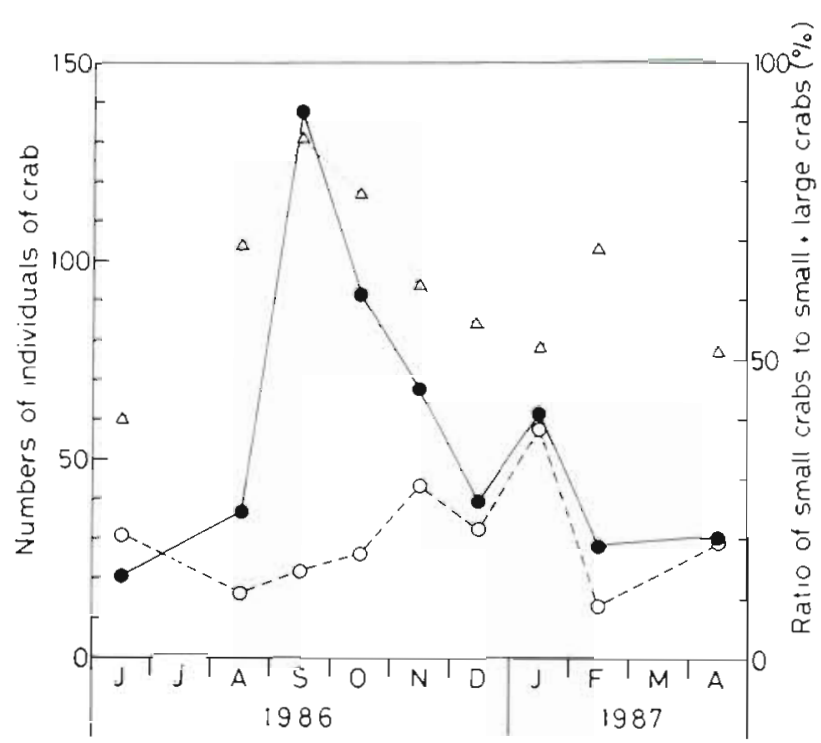

Fig. 1 Hemigrapsus penicillatus. Seasonal changes in numbers of small (carapace width $<1.3 \mathrm{~cm}$ ) and large crabs $(>1.3$ $\mathrm{cm}$ ) per basket filled with stones, and percentage of small crabs among total crabs. $\bullet-1$ Small crabs; ( $-\ldots$ ) large crabs; $(\Delta \ldots . . \Delta)$ percentage of small crabs

als $(\mathrm{CW}<1.3 \mathrm{~cm})$ and large individuals $(\mathrm{CW}>1.3 \mathrm{~cm})$, along with the percentage of small crabs among the total number of individuals. The percentage and the number of small crabs reached a maximum in September - the settling time of juvenile crabs - and then started to decrease after October. Between February and August of the following year, the population density of small crabs was stable at around 20 to 30 individuals per basket, and the percentage of small crabs fluctuated between 40 and $70 \%$. The density of large individuals per basket fluctuated between 12 and 60 throughout the year, and showed no clear profile of seasonal change.

Table 1 shows the numbers of individuals in the 4 boxes $10 \mathrm{~d}$ after setting. Box A appeared to reflect the normal density and ratio of small crabs to whole crabs under natural conditions. In Boxes $B, C$ and $D$, the total number of individuals did not differ much from that in Box A, suggesting a limitation in numbers of Hemigrapsus penicillatus capable of inhabiting these boxes. In other words, these results show the occurrence of interactions among $H$. penicillatus individuals, since the number of spaces for shelter formed by stones and wall may be greater than the number of crabs observed. Although the numbers of large crabs in Boxes $C$ and $D$ were the same, there were more small crabs in Box D (t-test; $p<0.05$ ), suggesting a decrease in interactions, or change in territorial behaviour due to lack of chelae. 
Table 1. Hemigrapsus penicillatus. Number of crabs of each carapace width (CW) per basket with stones and ratio of small individuals to all individuals from late October to late November 1986. Each value represents mean \pm SE of 4 determinations

\begin{tabular}{|c|c|c|c|c|}
\hline Type of basket & $\begin{array}{l}\text { Small crabs (S) } \\
0.1 \text { to } 1.3 \mathrm{~cm}\end{array}$ & $\begin{array}{c}\text { Large crabs (L) } \\
1.3 \text { to } 3.3 \mathrm{~cm}\end{array}$ & $\begin{array}{c}\text { Total } \\
(S+L)\end{array}$ & $\mathrm{S} / \mathrm{S}+\mathrm{L}$ \\
\hline Without netting $(\mathrm{A})$ & $13.0 \pm 6.7(100 \%)^{\circ}$ & $10.3 \pm 3.0(100 \%)$ & $23.3(100 \%)^{\circ}$ & 0.56 \\
\hline $\begin{array}{l}\text { With netting without } \\
\text { large crabs (B) }\end{array}$ & $22.8 \pm 9.2(175.4 \%)^{\circ}$ & $(0 \%)^{\circ}$ & $22.8(97.9 \%)^{\circ}$ & 1 \\
\hline $\begin{array}{l}\text { With netting with } \\
\text { large crabs (C) }\end{array}$ & $9.5 \pm 3.5(73.1 \%)^{\circ}$ & $10.0 \pm 0^{\cdots}(97.1 \%)^{\bullet}$ & $19.5(83.7 \%)^{\circ}$ & 0.49 \\
\hline $\begin{array}{l}\text { With netting with } \\
\text { large crabs lacking } \\
\text { chelae (D) }\end{array}$ & $15.0 \pm 1.9(115.4 \%)^{\circ}$ & $10.0 \pm 0^{*}(97.1 \%)^{*}$ & $25.0(107.3 \%)^{\circ}$ & 0.60 \\
\hline \multicolumn{5}{|c|}{ - Percentage of value for Box $A_{\text {; }} \quad$ From 2.1 to $2.5 \mathrm{~cm} \mathrm{CW}$} \\
\hline
\end{tabular}

\section{Laboratory observations}

Carapace widths of crabs preyed upon by predators of different sizes are shown in Fig. 2. For male predators, the size of the prey increased with the size of the predator. However, crabs could not prey upon individuals of the same size. Female predators tended strongly to prey upon the smallest crabs ( $\mathrm{CW} 0.5 \mathrm{~cm}$ ) regardless of the size of predator carapace width.

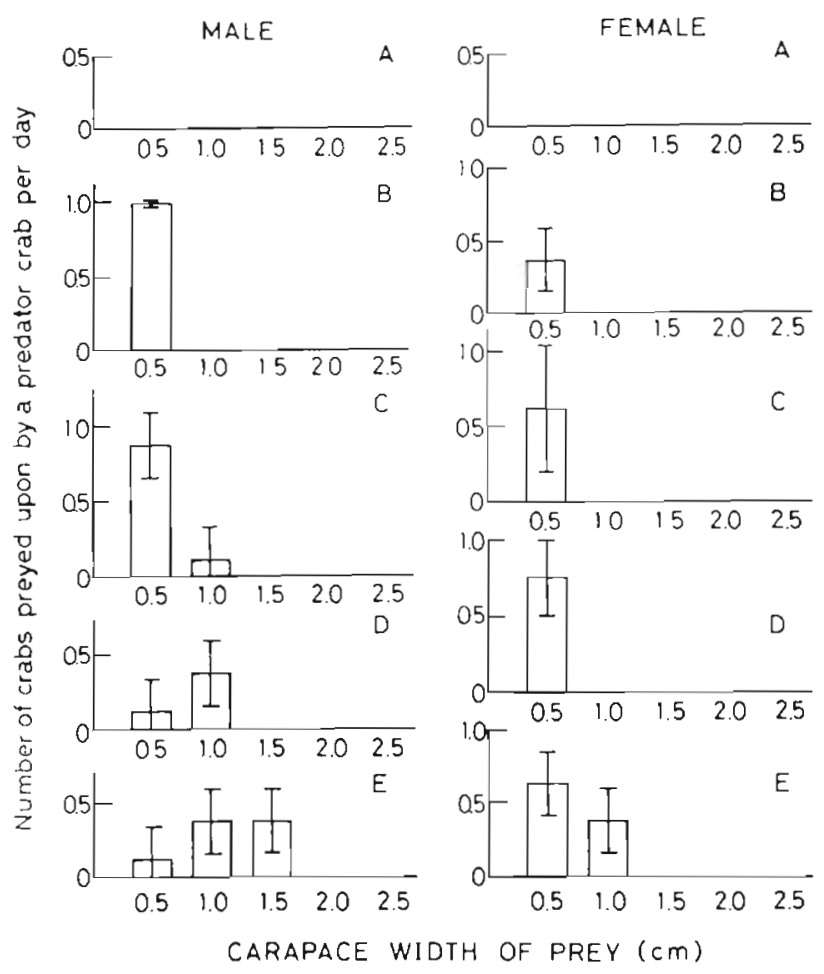

Fig. 2. Hemigrapsus penicillatus. Relation between carapace width of predators and that of prey (means $\pm \mathrm{SE}$ ). Carapace widths of predators were (A) $0.5 \mathrm{~cm}$; (B) $1.0 \mathrm{~cm}$; (C) $1.5 \mathrm{~cm}$; (D) $2.0 \mathrm{~cm}$; (E) $2.5 \mathrm{~cm}$
The maximum gape of chelae increased with the carapace widths of both males and females (Fig. 3). The gape increased more in males than in females: the gapes of large males and large females of CW $2.5 \mathrm{~cm}$ were 1.2 and $0.8 \mathrm{~cm}$ respectively.

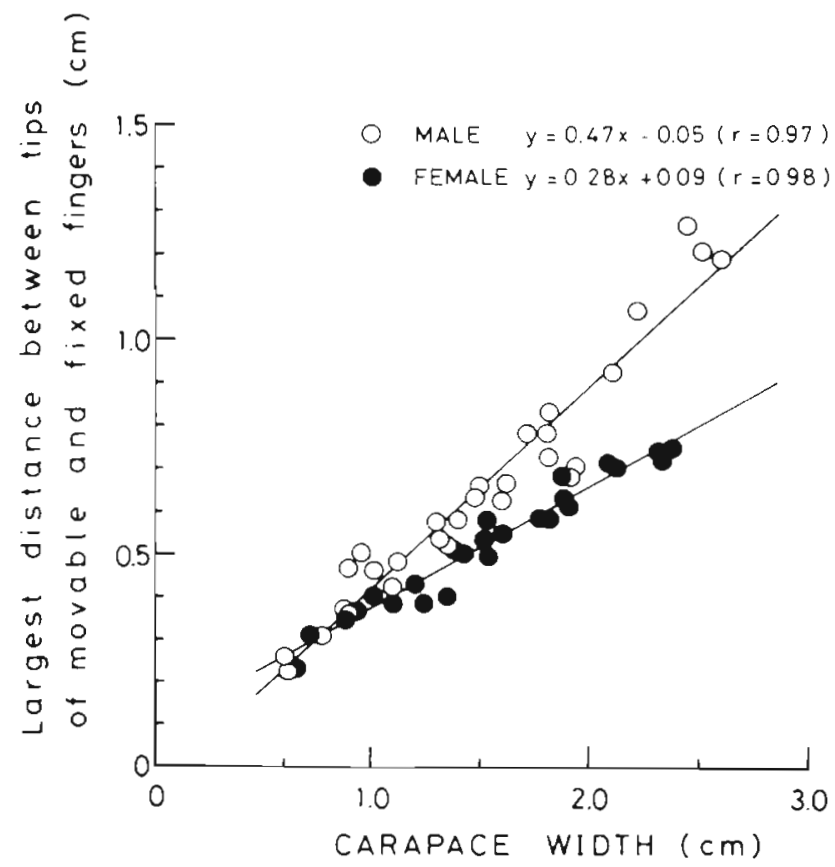

Fig. 3. Hemigrapsus penicillatus. Relation between carapace width and maximum distance between chelae tips in males and females

Fig. 4. shows the numbers of surviving small crabs, when 5 or 20 of these were placed in the boxes with 5 wide and 5 narrow pipes, together with 5 large crabs. The number remained almost constant in the box with 5 small crabs, but with 20 small crabs, the number of survivors decreased rapidly to 5 . This implies that each of the 5 narrow pipes was occupied by only $1 \mathrm{crab}$ and 


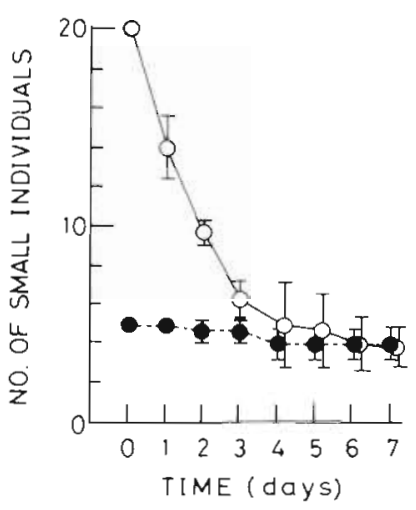

Fig. 4. Hemigrapsus penicillatus. Daily changes in number of prey in the presence of a predator (means $\pm \mathrm{SE}$ ). Initial number of prey was (O) 20 individuals, or (-) 5 individuals

that all the small crabs unable to enter and occupy the narrow pipes were preyed upon by large individuals. Thus shelter which only small individuals can enter plays an important role in preventing cannibalism.

Table 2 shows the effects of sessile matter on cannibalism. The predation of small individuals by large

Table 2. Hemigrapsus penicillatus. Effeect of sessile matter on survival of 10 small crabs in the presence of large ones

\begin{tabular}{llll} 
Experimental condition & \multicolumn{3}{c}{ No. of survivors } \\
& $5 \mathrm{~d}$ & $10 \mathrm{~d}$ & $15 \mathrm{~d}$ \\
\hline $\begin{array}{l}\text { Without sessile matter } \\
\text { With sessile matter }\end{array}$ & $5.3 \pm 7.7$ & $2.0 \pm 5.5$ & $0.3 \pm 1.2$ \\
$0^{\text {ns }}$ & $2.0 \pm 2.0^{\text {ns }}$ & \\
ns Not significant at $\mathrm{p}=0.05$ with & vs without sessile matter \\
on each observed day
\end{tabular}

ones was not affected by the sessile matter (t-test; $p$ $>0.05$, not significant).

Fig. 5 (Column A) shows the frequency of contact of small and large crabs as a result of wandering randomly, since crabs of both sizes had their eyes removed. This frequency was very high, suggesting that eyesight tends to decrease frequency of contact. Small crabs appear to avoid large ones visually, because the frequency of contact between large and small crabs became relatively high when the latter had no eyes (Columns A \& B) compared to individuals with normal eyes (Columns $C$ \& D). Large crabs seem to search for small crabs, since the contact frequency was lower for large crabs only without eyes (Column C) than for large crabs with eyes (Column D).

\section{DISCUSSION}

It is widely recognized that an intraspecies preypredator relationship exists among crabs (Mackay

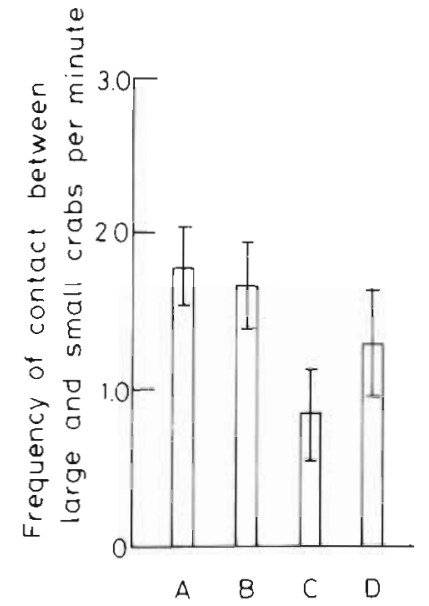

Fig. 5. Hemigrapsus penicillatus. Frequency of contact between small and large crabs (means \pm SE). A: eyes of both small and large crabs removed; $B$ : eyes of small crabs removed; $C$ : eyes of large crabs removed; $D$ : both small and large crabs normal

1942, Butler 1954, Gotshall 1977, Botsford \& Wickham 1978, Stevens et al. 1982). An examination of the relationship between the body sizes of prey and predators in Hemigrapsus penicillatus showed that the prey become larger with larger male predators, but that female predators preyed only on small individuals (Fig. 2 ). The maximum gape of the chelae is larger in males than in females (Fig. 3), suggesting that the size of prey depends on the gape of the predator's chelae. This inference is supported by studies on Carcinus maenus and Liocarcinus puber feeding on molluscs and shore crabs, where the size of food animals has been found to correspond to the size and features of the chelae of predator crabs (Elner \& Hughes 1978, Hughes \& EIner 1979, ap Rheinallt \& Hughes 1985, ap Rheinallt 1986).

Settling of juvenile Hemigrapsus penicillatus (CW ca $0.15 \mathrm{~cm}$ ) occurs in fall in the study area (Okamoto \& Kurihara 1987). This is clearly the cause of the rapid increase in small crabs $(\mathrm{CW}<1.3 \mathrm{~cm}$ ) in September, when the density of juvenile crabs reached around 110 individuals per basket, compared to about 40 crabs present before settling of juvenile crabs (Fig. 1). In general, crabs with $\mathrm{CW}<0.5 \mathrm{~cm}$ were frequently preyed upon, and those with $\mathrm{CW}>1.0 \mathrm{~cm}$ acted as predators (Fig. 2). The number of small crabs with $\mathrm{CW}$ $0.5 \mathrm{~cm}$ preyed upon by large crabs was calculated from the laboratory experiments as $0.55 \mathrm{~d}^{-1}$ on average: 0.53 individuals by a male and 0.59 individuals by a female predator (Fig. 2). If the 40 crabs inhabiting the basket in the field before the settling period of juveniles fed on only juvenile crabs, and with the same frequency as in laboratory observations, about 20 juveniles would be removed per day, amounting to approximately 600 individuals per month. The potential number of indi- 
viduals eaten thus far exceeds the actual number of juvenile crabs present after settling (Fig. 1), confirming that the rapid decrease in small crabs between September and October could be caused by predation of juvenile crabs by large ones.

In the case of Dungeness crab Cancer magister, it has also been reported that juvenile crabs after settling are preyed upon by larger crabs (Mackay 1942, Butler 1954, Gotshall 1977), and such cannibalism is an important factor in their mortality, along with larval mortality (Botsford \& Wickham 1978). Griffiths (1975) found that invertebrates feed frequently on food sources most abundantly present, supporting the possibility that larger Hemigrapsus penicillatus feed frequently on their juveniles during the settling period, since juvenile crabs were the most abundant food source in the basket in September (Fig. 1). Moreover, when the juvenile crabs were transferred into the box containing large crabs together with sessile matter as possibly the food source in the field, the juvenile crabs were preyed upon by large ones in spite of the presence of sessile matter (Table 2).

Our laboratory experiments showed that shelters are vital in avoiding cannibalism, and that Hemigrapsus penicillatus shows territorial behaviour among individuals with carapace width of the same size. In the field, the total numbers of small and large individuals did not differ much in the boxes with or without large crabs as predators, implying territorial behaviour under natural conditions (Table 1). The number of individuals in the basket was constant throughout the year, except in the fall when numerous juvenile crabs settled (Fig. 1). The number of crabs capable of inhabiting baskets containing 25 stones is probably controlled by the number of suitable spaces between stones and the range of territory. This in turn leads to the stability of density in the baskets throughout the year.

Before predation of small Hemigrapsus penicillatus by large ones, contact may occur between small and large individuals. Small crabs avoided large crabs visually, while large crabs approached small ones also visually (Fig. 5). Therefore, the avoidance of large individuals by small ones, and approach of large individuals to small ones due to eyesight, are considered impor- tant factors in cannibalism regulating the population density of $H$. penicillatus.

Acknowledgements. We cordially thank DrS. Takeda, Faculty of Science of Tohoku University, for his useful discussion. This study was partly supported by the Grant-in-Aid for Special Project Research of the Ministry of Education, Science and Culture, Japan (No. 62124007).

\section{LITERATURE CITED}

ap Rheinallt, T. (1986). Size selection by the crab Liocarcinus puber feeding on mussels Mytilus edulis and on shore crabs Carcinus maenas: the importance of mechanical factors. Mar. Ecol. Prog. Ser. 29: 45-53

ap Rheinallt, T., Hughes, R. N. (1985). Handling methods used by the velvet swimming crab Liocarcinus puber when feeding on molluscs and shore crabs. Mar. Ecol. Prog. Ser. 25: $63-70$

Botsford, L. W., Wickham, D. E. (1978). Behaviour of agespecific, density-dependent models and the northern California Dungeness crab (Cancer magister) fishery. J. Fish. Res. Bd Can. 35: 833-843

Butler, T. H. (1954). Food of the commercial crab in the Queen Charlotte Islands region. Fish. Res. Bd Can. Prog. Rep. Pac. Coast Stn 99: 3-5

Elner, R. W., Hughes, R. N. (1978). Energy maximization in the diet of the shore crab, Carcinus maenas. J. Anim. Ecol. 47 : 103-116

Fox, L. R. (1975). Cannibalism in natural populations. Ann. Res. Ecol. Syst. 6: 87-106

Gotshall, D. W. (1977). Stomach contents of northern California Dungeness crab, Cancer magister. Calif. Fish Game 63: 43-51

Griffiths, D. (1975). Prey availability and the food of predators. Ecology 56: 1209-1214

Hughes, R. N., Elner, R. W. (1979). Tactics of a predator, Carcinus maenas, and morphological responses of the prey, Nucella lapillus. J. Anim. Ecol. 48: 65-78

MacKay, D. C. G. (1942). The Pacific edible crab, Cancer magister. Bull. Fish. Res. Bd Can. 62: 1-32

Okamoto, K., Kurihara, Y (1987). Seasonal variation of population structure of Hemigrapsus penicillatus (De Haan) (Crustacea: Brachyura). Jap. J. Ecol. 37: 81-90 (Japanese; English summary)

Polis, G. A. (1981). The evolution and dynamics of intraspecific predation. Ann. Rev. Ecol. Syst. 12: 225-251

Stevens, B. G., Armstrong, D. A., Cusimano, R. (1982). Feeding habits of the Dungeness crab Cancer magister as determined by the index of relative importance. Mar. Biol. 72: $135-145$ 